\title{
Small Cell Neuroendocrine Tumor of the Larynx: Two Case Reports
}

\author{
Öztun TEMELLi,, ${ }^{1}$ Nihal KAPLAN BOZDAĞ, ${ }^{2}$ Ayşenur AKATLI, ${ }^{3}$ Serhat YASLIKAYA, ${ }^{4}$ Mustafa DíkilitTAŞ, ${ }^{2}$
}

'Department of Radiation Oncology, Inonu University, Faculty of Medicine, Malatya-Turkey

${ }^{2}$ Department of Medical Oncology, Inonu University, Faculty of Medicine, Malatya-Turkey

${ }^{3}$ Department of Pathology, Inonu University, Faculty of Medicine, Malatya-Turkey

${ }^{4}$ Department of Otolaryngology, Malatya Training and Research Hospital, Malatya-Turkey

\begin{abstract}
SUMMARY
Neuroendocrine tumors of the larynx account for $<1 \%$ of all laryngeal cancers. Laryngeal small cell carcinomas of the neuroendocrine type (SCNC) account for $<0.5 \%$ of all laryngeal tumors. We report two cases of 65- and 75-year old men with small cell carcinoma of the supraglottic larynx. The patients were treated with induction chemotherapy (cisplatin-etoposide) and chemoradiotherapy (cisplatin-etoposide). The first patient was alive until 26 months from diagnosis. However, multiple brain metastases developed in the second patient, and he died 16 months after diagnosis. Small cell neuroendocrine carcinomas are very aggressive neoplasms. A combination of platinum-based chemotherapy and radiotherapy is the mainstay of the treatment for SCNC, which is considered to be a systemic disease.

Keywords: Larynx; radiotherapy; small cell.

Copyright $\odot$ 2017, Turkish Society for Radiation Oncology
\end{abstract}

\section{Introduction}

Laryngeal cancer accounts for approximately $2 \%-5 \%$ of all cancers worldwide. Squamous cell carcinomas are the most common types, accounting for up to $85 \%-90 \%$ of all histopathological subtypes.[1] On the other hand, neuroendocrine tumors are the most common non-squamous neoplasms, which account for $<1 \%$ of all laryngeal cancers. [2] Among these, atypical carcinoid tumors are the most frequently encountered neoplasms. [3] In addition, laryngeal small cell carcinomas of the neuroendocrine type (SCNC) account for $<0.5 \%$ of all laryngeal tumors. Although these tumors are mostly reported in men in the sixth or seventh decade of life and in cigarette smokers and can involve all anatomical regions of the larynx, they most frequently involve the supraglottic region.[3-5]

The definite diagnosis is based on the detection of the typical neuroendocrine structure on histopathological examination and immunochemical staining. Pathological diagnosis of this entity may be delayed due to its less common nature. Treatment options include surgery, chemotherapy, and radiotherapy.[6]

Here, we report two cases of SCNC of the larynx who were successfully treated with a combination of chemotherapy and radiotherapy.

\section{Case Report}

A 65-year-old male patient with congenital blindness visited the otorhinolaryngology clinic complaining of throat pain. Laryngeal endoscopic examination revealed a smooth-surfaced mass which filled the right ventricular band. The histopathological evaluation of the biopsy specimens revealed cells with hyperchromatic nuclei and scant amount of cytoplasm showing 


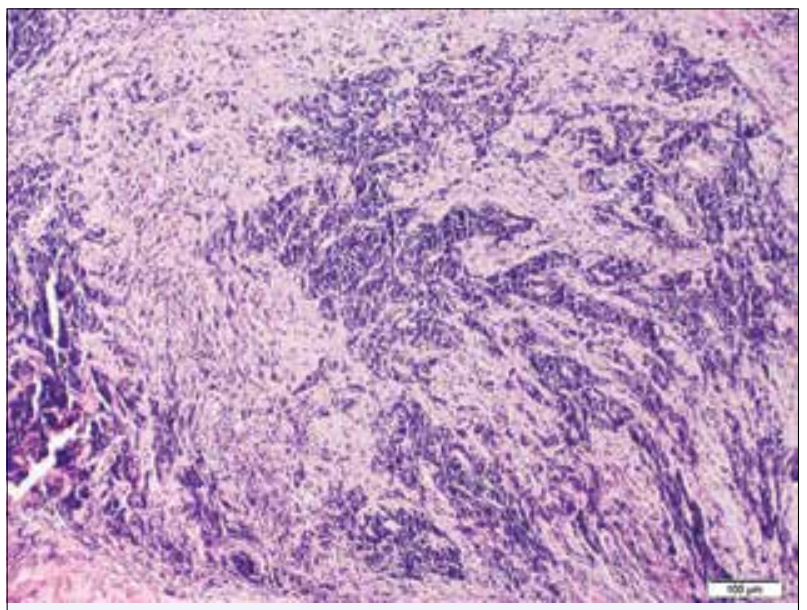

Fig. 1. Sheets of small cells showing crush artifact (H\&E; magnification, $100 \times$ ).

crush artifact (Fig. 1). Immunohistochemical examination showed that the tumor cells were positive for synaptophysin, pancytokeratin, and CD56. The Ki67 Labeling Index (LI) was 95\%, and immunohistochemistry for leukocyte common antigen (LCA) was negative. The diagnosis of SCNC was made based on histomorphological and immunohistochemical findings. Positron emission tomography/computed tomography (PET/CT) revealed a 3.7-cm (SUVmax: 21.9) invasive lesion penetrating the prevertebral area and bilateral level 2-3 supraventricular lymphadenopathy in the right supraglottic region (Fig. 2a-b). No distant metastasis was identified (T4bN2M0). Chemoradiotherapy following induction chemotherapy was recommended by the Head and Neck Tumor Committee, which consisted of a medical oncologist, otolaryngologist, and radiation oncologist. Laryngeal endoscopic and radiological evaluation performed after two cycles of cisplatin-etoposide $\left(80 \mathrm{mg} / \mathrm{m}^{2}\right.$ cisplatin-100 $\mathrm{mg} / \mathrm{m}^{2}$ etoposide) regimen demonstrated regression. Then, chemotherapy was completed at the end of the fourth cycle. A near complete response was achieved after chemotherapy on endoscopic examination and PET/ CT.

Subsequently, the patient was exposed to external radiotherapy targeted at the tumor bed at a dose of 66 Gy and at the bilateral level 1b, 2, 3, 4, 5a lymph nodes at a dose of 60 Gy using intensity modulated radiotherapy (IMRT) with a helical tomotherapy (HT) device. The treatment was planned to deliver $60 \mathrm{~Gy}$ in 30 fractions (Phase1) and 6 Gy boost in three fractions (Phase 2). Total treatment duration was 50 days.

Concurrent radiotherapy and three cycles of cisplatin- etoposide ( $80 \mathrm{mg} / \mathrm{m}^{2}$ cisplatin-100 $\mathrm{mg} / \mathrm{m}^{2}$ etoposide) were administered to the patient who had a good borderline Eastern Cooperative Oncology Group (ECOG) performance status of 3 . However, concurrent chemotherapy was discontinued following the development of grade 2 neutropenia. At 26 months, full response was achieved and no relapse was observed. Patient is followed up by endoscopic examination and MRI every 3 months.

\section{Case 2}

A 75-year-old male patient visited the otorhinolaryngology clinic with a complaint of non-resolving hoarseness since 2 months. Laryngeal endoscopic examination revealed a $2-\mathrm{cm}$ lesion extending from the epiglottis-laryngeal to the glottic surface. A biopsy specimen was obtained from the lesion, and histopathological examination revealed sheets of closely packed cells with scant cytoplasm and round/oval hyperchromatic nuclei. Immunohistochemistry result was diffusely positive for pancytokeratin, synaptophysin, and chromogranin-A. Immunohistochemistry results for LCA, high-molecular weight cytokeratin (HMWCK), and $\mathrm{p} 40$ were negative. The patient was diagnosed with a SCNC.

$\mathrm{CT}$ and PET/CT of the neck revealed a $2-\mathrm{cm}$ (SUVmax: 14.6) lesion localized anterior to the vocal cord. No lymph node or distant metastasis was reported (T2N0M0). Chemoradiotherapy following induction chemotherapy was recommended by the Head and Neck Tumor Committee. A near complete response was obtained after two cycles of cisplatin-etoposide regimen $\left(80 \mathrm{mg} / \mathrm{m}^{2}\right.$ cisplatin- $100 \mathrm{mg} / \mathrm{m}^{2}$ etoposide). Then, the patient was exposed to external radiotherapy targeted at the tumor bed at a dose of $66 \mathrm{~Gy}$ and at the bilateral level 2-3 lymph nodes at a dose of 60 Gy using IMRT with HT device. The treatment was planned to deliver $60 \mathrm{~Gy}$ in 30 fractions (Phase1) and 6 Gy boost in three fractions (Phase 2). Total treatment duration was 49 days.

Concurrent radiotherapy and one cycle of cisplatin-etoposide $\left(80 \mathrm{mg} / \mathrm{m}^{2}\right.$ cisplatin- $100 \mathrm{mg} / \mathrm{m}^{2}$ etoposide) were administered. No grade 3-4 toxicity was observed throughout the radiotherapy sessions. At 15 months after diagnosis, brain metastasis was observed, and the patient stopped responding to the treatment. He died at 16 months.

\section{Discussion}

Extrapulmonary SCNCs are relatively rare tumors, and are most commonly localized in the larynx of the 

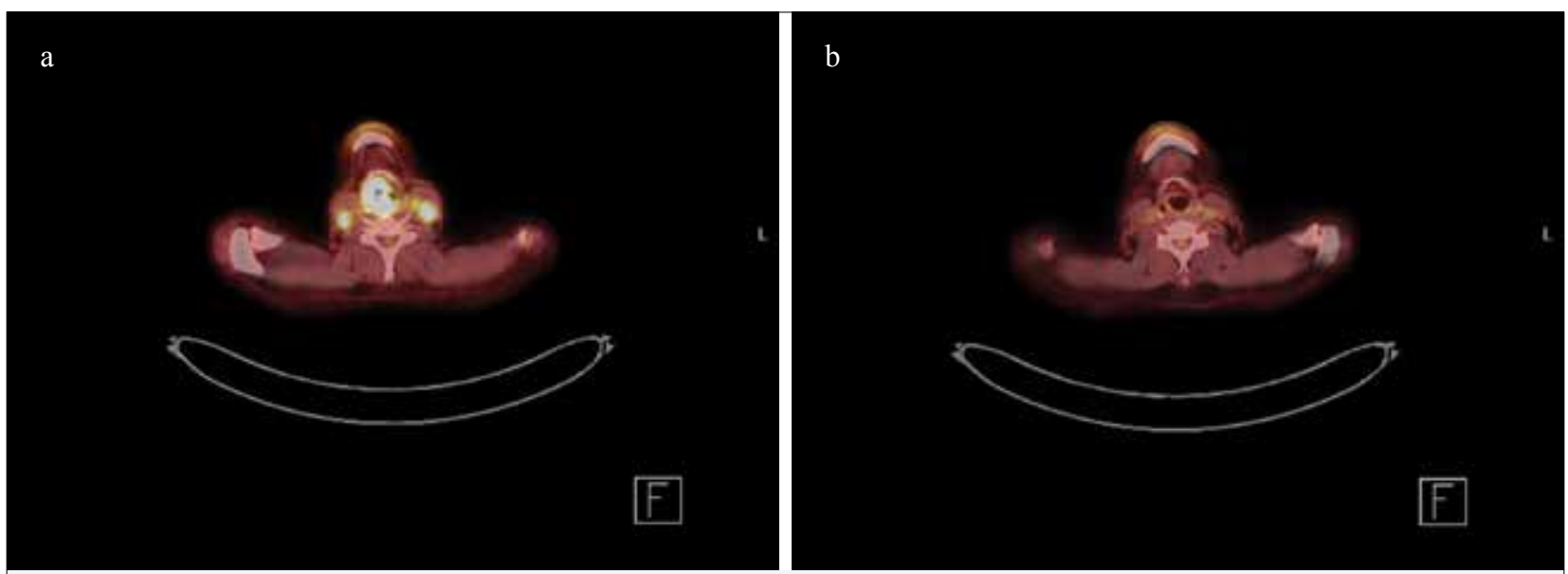

Fig. 2.(a-b) Pre-post treatment PET/CT images of case 1.

head-neck region. These tumors are mostly reported in men in the sixth or seventh decades of life and in cigarette smokers. Although these tumors can involve all anatomical regions of the larynx, they are most frequently localized in the supraglottic region.[3-5] The present cases were aged 65 and 75 years, were cigarette smokers, and their tumors were localized in the supraglottic region.

Laryngeal neuroendocrine neoplasia (LNN) represents $<1 \%$ of all laryngeal cancers. To date, $>700$ cases have been reported in literature.[7] LNN was first described in 1955 by Blanchard and Saunders, and was named a carcinoid.[8] Three years later, Olofsson and Van Nostrand first described SCNC of the larynx. [9] Among LNNs, the most common atypical carcinoid tumors are SCNCs, followed by paragangliomas, and typical carcinoid tumors. In 2005, the World Health Organization (WHO) classified neuroendocrine tumors of the head and neck into five groups: typical carcinoids, atypical carcinoids, SCNCs, combined small-non and small cell carcinomas, and paragangliomas. [10]

SCNCs are very aggressive neoplasms, and nearly half of the patients have cervical lymph node metastasis at presentation.[11] Approximately $60 \%-90 \%$ of the patients develop distant metastasis. The most common metastatic sites are the lungs, liver, and bones. Twoand five-year survival rates are $16 \%$ and $5 \%$, respectively.[4] In our report, one patient had cervical lymph node metastasis at presentation.

The treatment of SCNCs of the larynx remains controversial due to the small number of patients and lack of controlled studies. Surgical management of these neoplasms, including total laryngectomy and radical neck dissection, is less effective than that of squamous cell carcinomas, probably due to the high incidence of distant metastases in laryngeal SCNC patients.[12]

A combination of platinum-based chemotherapy and radiotherapy is the mainstay of the treatment of SCNC, which is a systemic disease.[13] In the study by Baugh et al. [14], the median survival of patients with laryngeal SCNC was reported to be up to 55 months following a definitive radiotherapy and adjuvant chemotherapy, which was significantly longer compared with other regimens $(p=0.02)$.[14] In a meta-analysis, van der Laan et al. also demonstrated that a combination of chemotherapy and radiotherapy had a higher five-year disease-specific survival (DSS) rate than those of other modalities (30.8\% vs $12.9 \%$; $\mathrm{p}=0.001)$.[13] In the aforementioned study, of the 436 laryngeal neuroendocrine cases; 183 were SCNC, $57.9 \%$ were located in the supraglottic area, while $66.7 \%$ were metastatic. Only $14 \%$ of the patients were surgically treated, while most patients (34.4\%) were treated with a combination of chemotherapy and radiotherapy. There was distant recurrence in $82.9 \%$ of the patients with or without the development of any local/regional failure. Five-year DSS and overall survival (OS) rates were found to be $5.5 \%$ and $4.7 \%$, respectively. Chemoradiotherapy yielded the best 5-year DSS for SCNCs compared with other modalities $(30.8 \%$ vs $12.9 \%$; $=0.001)$. In a review by Gnepp et al., five patients were treated with preoperative radiotherapy, four with radiotherapy alone, one with chemoradiotherapy, six with postoperative, and one with chemoradiotherapy. Mean survival time was 9.8 months (range, 1-26 months). The 2- and 5-year survival rates were $16 \%$ and $5 \%$, respectively.[15]

Furthermore, one of the most controversial issues in cases of extrapulmonary small cell carcinomas is the 
administration of prophylactic cranial irradiation (PCI). Brain metastasis is commonly observed in patients with SCLCs, and although PCI provides a 5.4\% survival advantage, brain metastasis is extremely rare in extrapulmonary SCNCs, and PCI is not routinely recommended.[16,17] However, our second case died due to brain metastasis.

\section{Conclusion}

Although laryngeal SCNCs are extremely rare, an early diagnosis is of utmost importance, because they have an aggressive biological behavior with a high potential for frequent distant metastases compared with squamous cell carcinomas. Tumors with submucosal localization and lymph node metastasis should particularly be considered in the differential diagnosis. A combination of chemotherapy and radiotherapy is considerably superior to surgical treatment due to the high sensitivity of laryngeal SCNCs to the combined regimens.

\section{Disclosure Statement}

Peer-review: Externally peer-reviewed.

Conflict of Interest: None declared.

Authorship contributions: Concept - O.T; Design - O.T; Supervision - A.A; Materials - N.K.B; Data collection \&/or processing - O.T; Analysis and/or interpretation - S.Y; Literature search - S.Y; Writing - O.T; Critical review - M.D

\section{References}

1. Ferlito A, Friedmann I. Squamous cell carcinoma. In: Ferlito A, editor. Neoplasms of the larynx. Edinburgh, UK: Churchill Livingstone; 1993. p. 113-33.

2. Lahoz Zamarro MT, Galve Royo A, Lázaro Maisanava JM. Neuroendocrine carcinoma of the larynx. Acta Otorrinolaringol Esp 1997;48(8):667-70.

3. Barnes L. Neuroendocrine tumours. In: Barnes L, Eveson JW, Reichart P, Sidransky D, editors. Pathology and genetics. Head and neck tumours. World Health Organization classification of tumours. Lyon: IARC Press; 2005. p. 135-9.

4. Gnepp DR. Small cell neuroendocrine carcinoma of the larynx. A critical review of the literature. ORL J Otorhinolaryngol Relat Spec 1991;53(4):210-9.

5. Michaels L, Hellquist HB. Nonepidermoid epithelial and neuroectodermal neoplasms. In: Michaels L, Hellquist HB, editors. Ear, Nose and Throat Histopathology. 2nd ed. London: Springer; 2001. p. 415-27.

6. Ferlito A, Rinaldo A. Small cell neuroendocrine carci- noma of the larynx: a preventable and frustrating disease with a highly aggressive lethal behavior. ORL J Otorhinolaryngol Relat Spec 2003;65(3):131-3.

7. Kumar LP, Armugham N, Krishna MR, Triveni B. Small-Cell Neuroendocrine Tumor of Larynx: A Rare Presentation. Indian J Otolaryngol Head Neck Surg 2015;1-6.

8. Blanchard CL, Saunders WH. Chemodectoma of the larynx; case report. AMA Arch Otolaryngol 1955;61(4):472-4.

9. Olofsson J, Van Nostrand AW. Anaplastic small cell carcinoma of larynx. Case report. Ann Otol Rhinol Laryngol 1972;81(2):284-7.

10. Barnes EL Jr. Neuroendocrine tumours. In: Barnes EL Jr, Eveson JW, Reichart P, Sidranksy D, editors. World Health Organization Classification of Tumours Pathology and Genetics of Head and Neck Tumours. Lyon: IARC Press; 2005. p. 135-9.

11. Ferlito A, Shaha AR, Rinaldo A. Neuroendocrine neoplasms of the larynx: diagnosis, treatment and prognosis. ORL J Otorhinolaryngol Relat Spec 2002;64(2):10813.

12. Coca-Pelaz A, Devaney KO, Rodrigo JP, Halmos GB, Strojan P, Mendenhall WM, et al. Should patients with laryngeal small cell neuroendocrine carcinoma receive prophylactic cranial irradiation? Eur Arch Otorhinolaryngol 2016;273(10):2925-30.

13. van der Laan TP, Plaat BE, van der Laan BF, Halmos GB. Clinical recommendations on the treatment of neuroendocrine carcinoma of the larynx: A meta-analysis of 436 reported cases. Head Neck 2015;37(5):707-15.

14. Baugh RF, Wolf GT, Beals TF, Krause CJ, Forastiere A. Small cell carcinoma of the larynx: results of therapy. Laryngoscope 1986;96(11):1283-90.

15. Gnepp DR, Ferlito A, Hyams V. Primary anaplastic small cell (oat cell) carcinoma of the larynx. Review of the literature and report of 18 cases. Cancer 1983;51(9):1731-45.

16. Aupérin A, Arriagada R, Pignon JP, Le Péchoux C, Gregor A, Stephens RJ, et al. Prophylactic cranial irradiation for patients with small-cell lung cancer in complete remission. Prophylactic Cranial Irradiation Overview Collaborative Group. N Engl J Med 1999;341(7):47684.

17. Walenkamp AM, Sonke GS, Sleijfer DT. Clinical and therapeutic aspects of extrapulmonary small cell carcinoma. Cancer Treat Rev 2009;35(3):228-36. 